\title{
Bjerknes-like Compensation in the Wintertime North Pacific
}

\author{
STUART P. BISHOP \\ California Institute of Technology, Pasadena, California \\ FRANK O. BRYAN AND R. JUSTIN SMALL \\ National Center for Atmospheric Research,* Boulder, Colorado
}

(Manuscript received 5 August 2014, in final form 18 February 2015)

\begin{abstract}
Observational and model evidence has been mounting that mesoscale eddies play an important role in airsea interaction in the vicinity of western boundary currents and can affect the jet stream storm track. What is less clear is the interplay between oceanic and atmospheric meridional heat transport in the vicinity of western boundary currents. It is first shown that variability in the North Pacific, particularly in the Kuroshio Extension region, simulated by a high-resolution fully coupled version of the Community Earth System Model matches observations with similar mechanisms and phase relationships involved in the variability. The Pacific decadal oscillation (PDO) is correlated with sea surface height anomalies generated in the central Pacific that propagate west preceding Kuroshio Extension variability with a $\sim 3-4-y r$ lag. It is then shown that there is a near compensation of $O(0.1) \mathrm{PW}\left(\mathrm{PW} \equiv 10^{15} \mathrm{~W}\right)$ between wintertime atmospheric and oceanic meridional heat transport on decadal time scales in the North Pacific. This compensation has characteristics of Bjerknes compensation and is tied to the mesoscale eddy activity in the Kuroshio Extension region.
\end{abstract}

\section{Introduction}

Earth's climate system is rich with natural climate variations that vary on interannual to decadal time scales (e.g., El Niño-Southern Oscillation and North Atlantic Oscillation). At times, this internal variability can even mask the forced anthropogenic global warming signal such as the recent global warming "hiatus" thought to be tied to ocean heat uptake in the equatorial Pacific (Kosaka and Xie 2013; England et al. 2014). Understanding interannual to decadal variability is key to understanding and predicting global climate change.

One form of natural climate variation from air-sea interaction was proposed by Bjerknes (1964) for meridional heat transport in the North Atlantic. Bjerknes argued that if the net top-of-atmosphere radiation $Q_{\mathrm{TOA}}$ was in

\footnotetext{
* The National Center for Atmospheric Research is sponsored by the National Science Foundation.

Corresponding author address: Stuart P. Bishop, California Institute of Technology, 1200 E. California Blvd., Pasadena, CA 91125. E-mail: sbishop@caltech.edu
}

balance then for decades when the Atlantic meridional overturning circulation was stronger than in others, there would be an increase in meridional ocean heat transport and a compensating decrease in the atmospheric meridional heat transport in the Northern Hemisphere. This compensation in meridional heat transport was later termed "Bjerknes compensation." Since the North Pacific is not a site of deep-water formation, it was argued that the North Atlantic would be more favored to observe this compensation and has been the focus of previous studies (e.g., Farneti and Vallis 2013).

In recent years, the mesoscale characteristics of the Kuroshio Extension system in the North Pacific have been observed to vacillate between weakly meandering (stable) and strongly meandering (unstable) states on decadal time scales (Qiu and Chen 2005). This variability has been shown to be correlated with the Pacific decadal oscillation (PDO) with 3-4-yr lag (Qiu and Chen 2010). The mechanism linking variations in PDO to Kuroshio Extension variability is still an active area of research, but notable work by Qiu and Chen (2010) and Sasaki et al. (2013) point to the importance of sea surface height (SSH) anomalies and wind stress curl patterns associated with strengthening and weakening of the Aleutian low 
in the central North Pacific. The Kuroshio Extension System Study (KESS) was a large-scale field program from 2004 to 2006 that observed a transition from a stable to unstable state at the end of 2004 (Donohue et al. 2008). The meridional eddy heat transport $\mathscr{H}_{\text {eddy }}$ between $144^{\circ}$ and $148^{\circ} \mathrm{E}$, calculated from the KESS data is 3 times larger during the unstable versus stable regime (Bishop 2013). The KESS data record is short, but this relationship may hold for other transitions between meandering states.

Current ocean climate simulations are routinely run with ocean resolution $\sim 1^{\circ}$, which requires that the transport by mesoscale eddies be parameterized (e.g., Gent and McWilliams 1990). The mesoscale is the most energetic scale in the ocean, with time scales of days to months and length scales of tens to hundreds of kilometers. High-resolution, mesoscale-resolving climate simulations are currently in an exploratory phase of research. A key finding of resolving mesoscale eddies is a sharpening of oceanic fronts, which have important feedbacks on the atmospheric circulation through air-sea interactions (Bryan et al. 2010). These ocean feedbacks are strongest in the vicinity of western boundary currents (WBCs; e.g., Gulf Stream and Kuroshio Extension).

New evidence is emerging on the importance of western boundary currents in air-sea interaction and atmospheric, transient eddy heat fluxes (Kwon and Joyce 2013; Kelly et al. 2010). Small et al. (2013) ran a series of experiments with the Community Atmosphere Model (CAM), version 4, with smoothed and unsmoothed sea surface temperature (SST) boundary conditions from the $0.25^{\circ}$ Reynolds et al. (2007) analysis of satellite and in situ data for years 2002-09. They found a local maximum increase of $20 \%-40 \%$ in atmospheric, meridional, transient eddy heat fluxes in the unsmoothed versus smoothed SST over the Gulf Stream and Antarctic Circumpolar Current. The increase in atmospheric eddy heat flux coincided with stronger SST gradients in the unsmoothed case. Using reanalysis products, O'Reilly and Czaja (2015) also found that the meandering state of the Kuroshio Extension results in enhanced, vertically integrated, atmospheric, meridional eddy heat flux during stable regimes compared with unstable regimes. The difference is reflected in stronger SST gradients and ocean-to-atmosphere surface heat fluxes $Q_{o}$ during the stable versus unstable regimes.

The atmospheric response to oceanic variability at the mesoscale and KESS observations suggests there is a degree of Bjerknes-like compensation between the atmospheric and oceanic meridional heat transport in the North Pacific, but a lack of ocean observations makes this calculation difficult. In this paper, we use a fully coupled high-resolution climate simulation of the
Community Earth System Model (CESM) to quantify the degree of compensation between atmospheric and oceanic meridional heat transport in the North Pacific. What we mean by "Bjerknes-like" compensation is that our interest in a "local" compensation is not strictly Bjerknes compensation because our analysis deviates from the global volume integral in the formal derivation. We summarize the formal derivation of Bjerknes compensation in the next section as merely guidance in our interpretation of meridional heat compensation in the North Pacific. The ocean component of CESM is well suited to address this question because it has been shown to represent eddymean flow interactions and oceanic $\mathscr{B}$ eddy well compared to KESS observations (Bishop and Bryan 2013) as well as other characteristics of the Kuroshio Extension system (Delman et al. 2015; Douglass et al. 2012a,b; Jayne et al. 2009; Rainville et al. 2007).

The paper is organized as follows: In section 2, the theory of Bjerknes compensation is summarized. In section 3, the model and observational datasets are described. In section 4, the Kuroshio Extension variability in the model is compared with observations and an index of Kuroshio Extension "waviness" is quantified. Section 5 looks at composites of the atmospheric response of $Q_{o}$ and atmospheric transient eddy heat flux during the winter months based on the waviness index. Only the wintertime atmospheric response is quantified in this study because it is expected that the response will be most notable during this time when synoptic storms follow the Kuroshio Extension front closely. To be consistent with previous studies (e.g., Kwon and Joyce 2013), the convention for wintertime is boreal winter for the months January-March (JFM). Section 6 presents the oceanic meridional transport composites based on the waviness index. The paper concludes with implications for Bjerknes compensation in the North Pacific in section 7 , the discussion and conclusions section.

\section{Bjerknes compensation theory}

The concept of Bjerknes compensation is demonstrated by taking a volume integral of the steady-state temperature equation. The steady-state temperature equation in flux form for the atmosphere or ocean is

$$
\boldsymbol{\nabla} \cdot \overline{\mathbf{u} T}+\frac{\partial \overline{w T}}{\partial z}=\frac{1}{\rho C_{p}} \frac{\partial \bar{Q}}{\partial z},
$$

where $\boldsymbol{\nabla}=\left(\partial_{x}, \partial_{y}\right)$ is the two-dimensional gradient operator; $T$ is temperature; $\mathbf{u}=(u, v)$ is the horizontal velocity; $w$ is the vertical velocity; $\rho$ is the fluid density; $C_{p}$ is the fluid specific heat at constant pressure; $Q$ represents vertical mixing processes and other radiational 
sources or sinks; and a bar indicates a time average. For the ocean, we can take $T \approx \theta$, but for the moist atmosphere, $T$ needs to be replaced with

$$
T=\theta+L q,
$$

where $\theta$ is the potential temperature, $L$ is the latent heat of vaporization, and $q$ is the specific humidity. Equation (1) is integrated over the volume of a polar cap north of some latitude separately for the ocean and atmosphere to yield two equations. The steady-state heat balance for the ocean under the Boussinesq approximation is

$$
\int_{S} \int_{-h_{o}}^{0} \nabla \cdot\left(\rho_{o} C_{p}^{o} \overline{\mathbf{u}_{o} T_{o}}\right) d z d S=\int_{S} \bar{Q}_{o} d S,
$$

where the subscript and superscript $o$ indicates ocean; $\rho_{o}$ is the averaged density; $C_{p}^{o}$ is the specific heat for seawater; $h_{o}$ is the ocean depth; and $S$ is the surface area under the polar cap. The boundary conditions of $w=$ 0 at $z=0,-h_{o}$ were used, and the fluxes across the ocean sea floor $Q_{-h_{o}}$ are assumed negligible. The heat balance for the atmosphere is

$$
\int_{S} \int_{0}^{h_{a}} \nabla \cdot\left(\rho_{a} C_{p}^{a} \overline{\overline{\mathbf{u}_{a} T_{a}}}\right) d z d S=\int_{S} \Delta \bar{Q} d S,
$$

where the subscript and superscript $a$ indicates atmosphere, and $\Delta \bar{Q}=\bar{Q}_{\mathrm{TOA}}-\bar{Q}_{o}$ is the difference between TOA radiation and net ocean-to-atmosphere surface flux. The boundary conditions of $w=0$ at $z=0, h_{a}$ were also used. Adding Eqs. (3) and (4) and applying Gauss's theorem you arrive at

$$
\mathscr{H}^{o}+\mathscr{H}^{a}=\int_{S} \bar{Q}_{\mathrm{TOA}} d S
$$

where $\mathscr{H}^{o}$ is the oceanic meridional heat transport

$$
\mathscr{H}^{o} \equiv \oint \int_{-h_{o}}^{0} \rho_{o} C_{p}^{o} \overline{v_{o} T_{o}} d z d x,
$$

and $\mathscr{H}^{a}$ is the atmospheric meridional heat transport

$$
\mathscr{H}^{a} \equiv \oint \int_{0}^{h_{a}} \rho_{a} C_{p}^{a} \overline{v_{a} T_{a}} d z d x
$$

Finally, if there is no net change in TOA radiation $\left(\delta \int_{S} \bar{Q}_{\mathrm{TOA}} d S=0\right)$, and no change in heat storage, changes in $\mathscr{H}^{o}$ will counterbalance changes in $\mathscr{H}^{a}$ :

$$
\delta \mathscr{H}^{o}=-\delta \mathscr{H}^{a} .
$$

This is the basic statement of Bjerknes compensation. Note that while this analysis is for the global system, we will examine the compensation hypothesis in a more localized way, restricting the budgets to the North Pacific sector, and hence refer to compensation as Bjerknes-like. The regions of interest will be the latitudes spanning the Kuroshio Extension and jet stream in the North Pacific sector between $25^{\circ}$ and $50^{\circ} \mathrm{N}$.

\section{Model and observational datasets}

\section{a. High-resolution fully coupled model}

The model used in this study is a high-resolution version of CESM (Hurrell et al. 2013), a new generation climate system model that is the successor to the Community Climate System Model, version 4 (Gent et al. 2011). Details of the simulation examined are summarized below, but for a more in-depth description, see Small et al. (2015). The model configuration used here is CAM, version 5, with a spectral element dynamical core; Community Ice Code, version 4 (Hunke and Lipscomb 2008); Parallel Ocean Program version 2 (POP2); and the Community Land Model, version 4 (Lawrence et al. 2011). CAM5 has a horizontal resolution of about $0.25^{\circ}$ (specifically the spectral element dynamical core with 120 elements on each face of the cubed sphere, referred to as ne120) and 30 levels in the vertical.

The POP2 model has nominal grid spacing of $0.1^{\circ}$ (decreasing from $11 \mathrm{~km}$ at the equator to $2.5 \mathrm{~km}$ at high latitudes) on a tripole grid with poles in North America and Asia. The configuration was similar to that used in McClean et al. (2011) and Kirtman et al. (2012), except that the number of vertical levels was increased from 42 to 62 , with more levels in the main thermocline. The ocean communicated with the coupler, providing updated SST and surface currents and receiving updated surface fluxes, every $6 \mathrm{~h}$, and the atmosphere communicated 144 times each day (10 $\mathrm{min})$. The coupler computes air-sea fluxes using the Large and Yeager (2009) surface layer scheme. The land and sea ice models were run at the same resolution and grid as the atmosphere and ocean models, respectively. The high-resolution CESM was run under "present-day (year 2000)" greenhouse gas conditions (fixed $\mathrm{CO}_{2}$ concentration of $367 \mathrm{ppm}$ ). The simulation was run for $86 \mathrm{yr}$ with $15 \mathrm{yr}$ of spinup for a total of $101 \mathrm{yr}$ and initialized with WOCE climatology derived from Gouretski and Koltermann (2004). The model years in this analysis will refer to the last $86 \mathrm{yr}$ of the simulation with model year 1 being equivalent to aggregate simulation year 16. Time averages and covariances of threedimensional variables for the atmosphere and ocean were archived monthly. A few two-dimensional surface fields, including SST and SSH, were saved daily for model years $46-86$. 

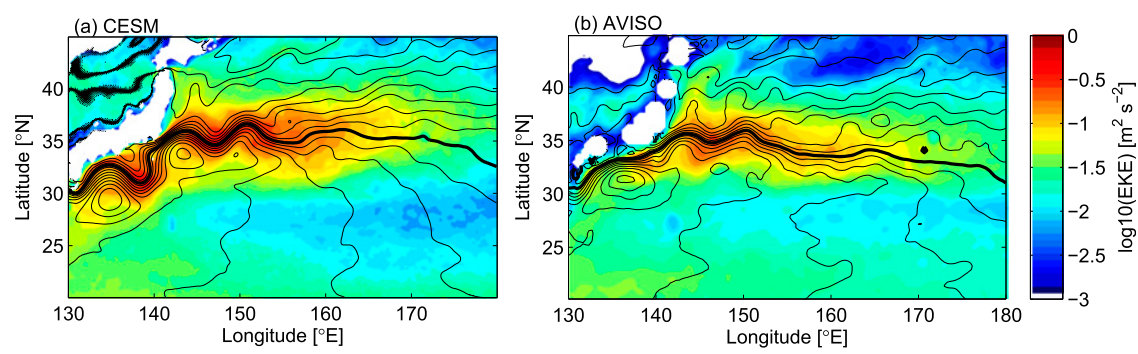

FIG. 1. Time-mean EKE and SSH from the model and observations. (a) CESM 20-yr average for model years 46-66 and (b) AVISO October 1992-April 2012 time average for EKE (color contours, contour interval (ci) $=100 \mathrm{~cm}^{2} \mathrm{~s}^{-2}$ ) and SSH (black contours, ci $=10 \mathrm{~cm}$ ). The thick black contours in (a) and (b) are the 60- and 100-cm SSH contours, respectively, and represent the Kuroshio Extension axis.

\section{b. Observational datasets}

Three observational datasets are used for comparison with CESM: SSH, SST, and $Q_{o}$. The multimission satellite altimetry SSH anomaly product produced by SSALTO/DUACS and distributed by the Archiving, Validation, and Interpretation of Satellite Oceanographic Data (AVISO) with support from the Centre National d'Etudes Spatiales was used. To obtain absolute SSH, the MDT_CNES-CLS09 mean dynamic topography was added to the SSH anomaly, which was produced by the Collecte Localisation Satellites Space Oceanography Division and distributed by AVISO. This SSH product uses all available satellite altimeters after October 1992, providing a $1 / 3^{\circ}$ longitude Mercator gridded dataset every 7 days (Ducet and Le-Traon 2001). The SSH data used is for the time period from 14 October 1992 to 18 April 2012.

The Hadley Centre Sea Ice and Sea Surface Temperature dataset (HadISST) was used for SST to calculate PDO index. HadISST has monthly analyses with a $1^{\circ}$ latitude-longitude spatial grid from 1870 to present. Only the data coincident with the SSH data from 1992 to 2012 are used.

The Woods Hole Oceanographic Institution objectively analyzed air-sea fluxes (OAFlux) product was used for $Q_{o}$ (Yu and Weller 2007). The OAFlux product is a monthly mean, $1^{\circ}$ gridded dataset available from 1958 to present. Again, only the data coincident with the SSH data were used.

\section{Kuroshio Extension variability}

It is now well documented that the mesoscale variability in the upstream region of the Kuroshio Extension (141 $153^{\circ} \mathrm{E}$ ) vacillates between weakly (stable) and strongly (unstable) meandering states on interannual to decadal time scales (Qiu et al. 2014; Qiu and Chen 2010, 2005). The link between these meandering states is correlated with the PDO (Qiu and Chen 2005). Depending on the phase of the PDO, first-mode baroclinic Rossby waves are generated in the central North Pacific and propagate west as positive and negative SSH anomalies. Positive SSH anomalies force the Kuroshio Extension north during stable states, and negative anomalies force the Kuroshio Extension south during unstable states, with $\sim 3-4-y r$ lag between PDO phase and meandering state transition. In this section, we compare the model mesoscale variability with observations based on the PDO arguments in Qiu and Chen (2005) and define a Kuroshio Extension index (KEI) in order to objectively distinguish between meandering states.

\section{a. Mesoscale eddies and decadal variability}

The kinetic energy associated with mesoscale eddies is highest in the vicinity of the western boundary current extensions and Southern Ocean. Time-mean SSH and surface eddy kinetic energy (EKE) are shown in Fig. 1 for CESM and observations. EKE for both model and observations is calculated as

$$
\mathrm{EKE}=\frac{1}{2} \overline{\left(u_{g}^{\prime 2}+v_{g}^{\prime 2}\right)},
$$

where primes indicate a deviation from the time mean, and the geostrophic velocities $\left(u_{g}, v_{g}\right)$ are calculated from gradients in $\mathrm{SSH}(\eta)$ :

$$
\mathbf{u}_{g}=\frac{g}{f} \mathbf{k} \times \nabla \eta,
$$

where $g$ is the acceleration due to gravity; $f$ is the Coriolis parameter; $\mathbf{k}$ is the local vertical unit vector aligned with $g$; and $\boldsymbol{\nabla}$ is the gradient operator. EKE from the AVISO product was calculated from a 7-day, objectively mapped SSH product. To best match the AVISO product, EKE in CESM was calculated from Eqs. (9) and (10) using daily SSH that was additionally 7-day averaged for $20 \mathrm{yr}$ (model years 46-66). CESM has 

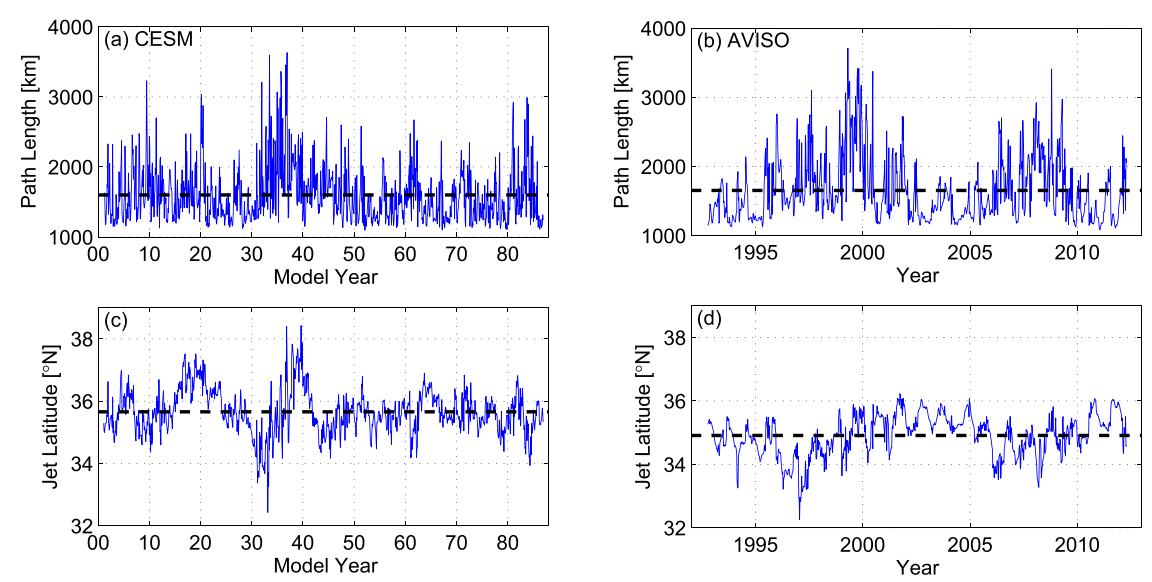

FIG. 2. Kuroshio Extension interannual to decadal variability in the model compared with observations. Pathlength and jet latitude respectively for (a),(c) CESM and (b),(d) AVISO. The thick, dashed, black line in each figure is the respective mean.

slightly elevated EKE levels during this time period (Fig. 1a), but the general geographic structure of EKE and SSH is similar to observations (Fig. 1b). The point of Fig. 1 is merely to demonstrate that the model exhibits similar amplitudes and geographic patterns of EKE as observations.

As mentioned earlier, the Kuroshio Extension exhibits interannual to decadal transitions between weakly and strongly meandering states. To look at this variability in the model, pathlength and jet axis latitude are calculated using SSH similar to Qiu and Chen (2005). Pathlength is used as an index for variability because it is proportional to EKE; a short pathlength indicates a less meandering Kuroshio Extension path, and a longer pathlength indicates more meandering. Pathlength is calculated as the distance between $141^{\circ}$ and $153^{\circ} \mathrm{E}$ of the jet axis $(60-\mathrm{cm}$ contour in CESM and $100-\mathrm{cm}$ contour in AVISO in Fig. 1). To distinguish between closed-contour features, for example, cold-core rings, and the Kuroshio Extension path at each time step, the contour with end points at $141^{\circ}$ and $153^{\circ} \mathrm{E}$ was used to calculate pathlength.

The time series of pathlength and the average latitude of the jet axis between are shown in Fig. 2 for CESM and observations. Pathlength in CESM (Fig. 2a) exhibits similar transitions from weakly to strongly meandering states as seen from the AVISO product (Fig. 2b). The analysis for the paper from here on will focus on model years 45-86, during which $Q_{\mathrm{TOA}}$ had reached equilibrium (Small et al. 2015) and the variance better matched observations. The mean and standard deviation of pathlength for this time in CESM is $1580 \pm 358 \mathrm{~km}$ compared with $1652 \pm 461 \mathrm{~km}$ from AVISO. The spectrum for the pathlength from CESM also agrees with observations (Fig. 3b). The variance is higher in observations, but it will be shown below that the fraction of the variance agrees in frequency space.
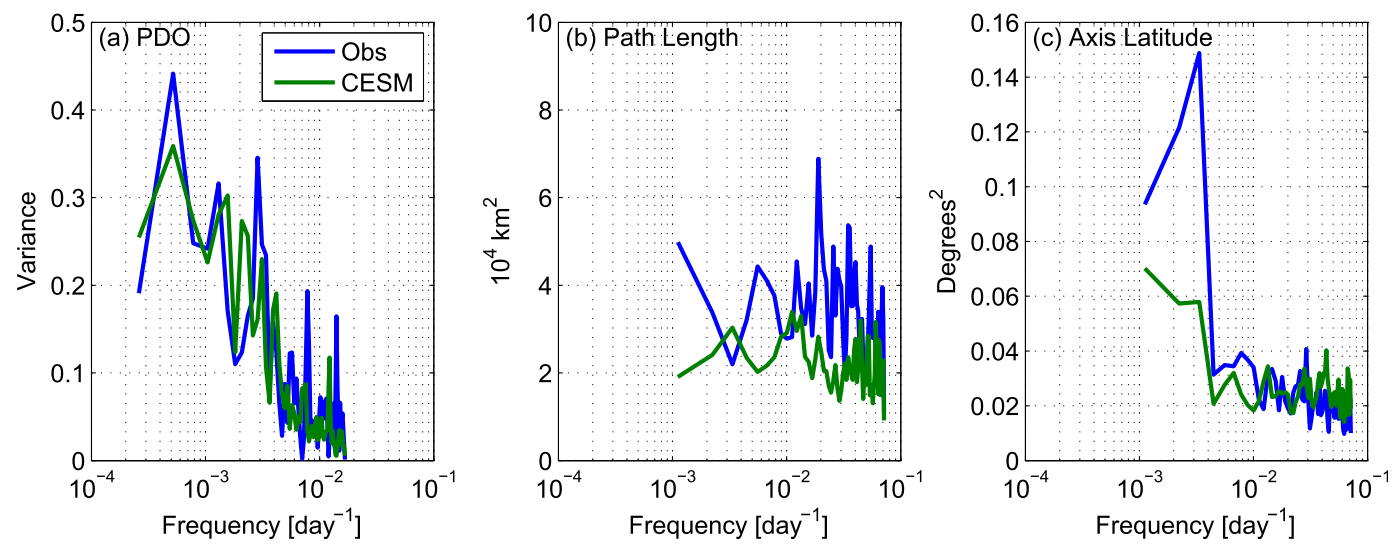

FIG. 3. Variance-preserving power spectral density comparisons for the model (model years 45-86) and observations. (a) PDO, (b) pathlength, and (c) jet axis latitude. Welch's method of spectral estimation was used with a sampling frequency $\mathrm{Fs}=1 / 30$ day $^{-1}$ for PDO and $\mathrm{Fs}=1 / 7$ day $^{-1}$ for pathlength and jet axis latitude, segment length of 128 days, Hanning window, and $50 \%$ overlap. 

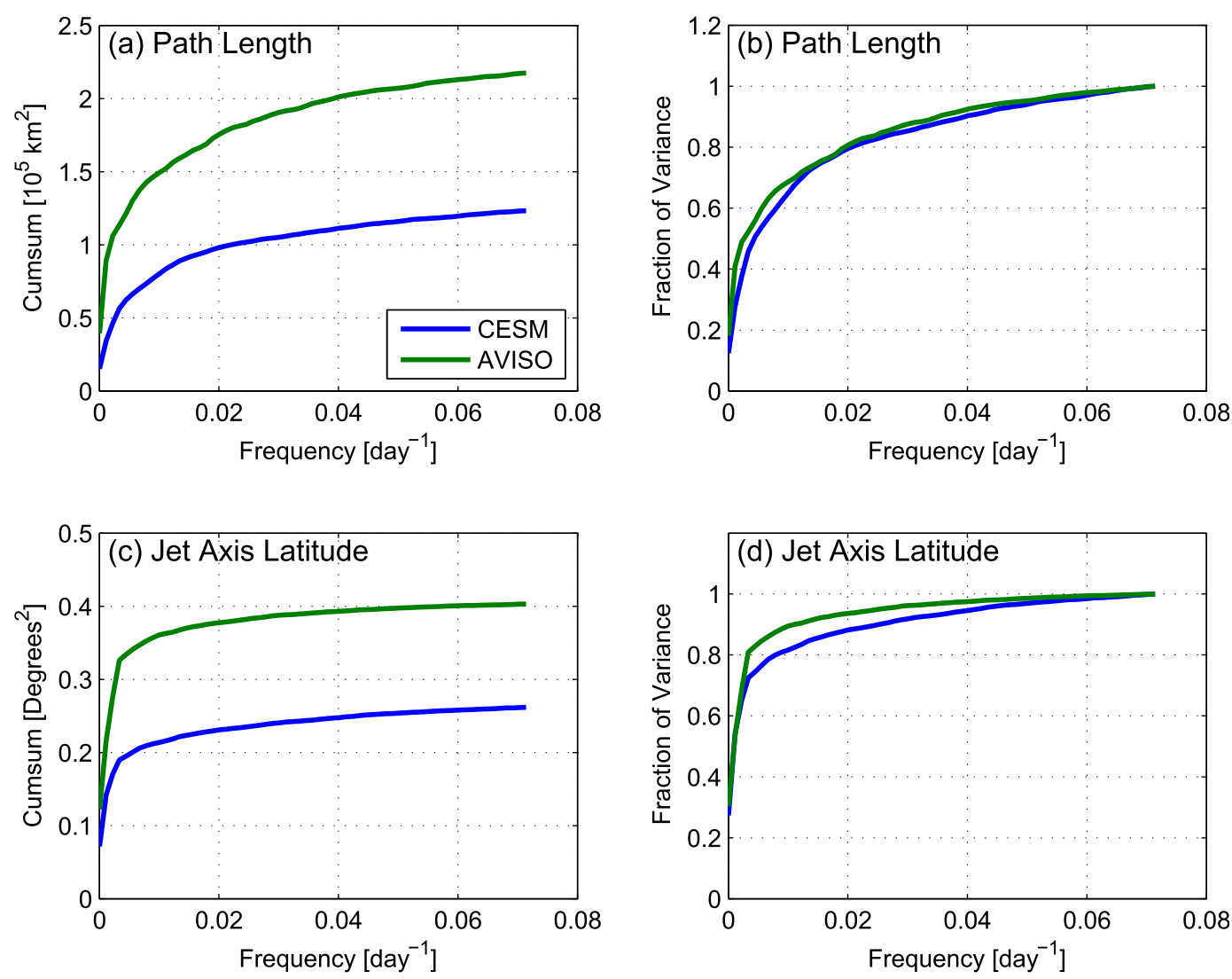

FIG. 4. Cumulative sum of power spectral density and fraction of variance as a function of frequency for pathlength and jet axis latitude in CESM and observations. (a) Cumulative sum of pathlength power spectral density. (b) Fraction of variance pathlength. (c),(d) As in (a) and (b), but for jet axis latitude.

An insightful way to look at the spectrum is by calculating the cumulative sum of the power spectral density. For example, the respective variance $\sigma^{2}$ for PDO, pathlength, and jet axis latitude is equal to the area under the curve in Fig. 3:

$$
\sigma_{x}^{2}(f)=\sum_{i}^{\infty} P_{x x_{i}} \Delta f_{i}
$$

where $P_{x x}$ is the power spectral density of $x$, for example, pathlength, and $\Delta f$ is the increment between frequencies. The frequency increment for pathlength and jet axis latitude is $\Delta f=0.011$ cycles per day. The cumulative sum of the pathlength as a function of frequency is shown in Fig. 4 a for CESM and observations. Both curves for the cumulative sum have a similar shape as a function of frequency, but the observations have higher values. This is reflective in the observations having a higher variance; the last value of the cumulative sum at the highest frequency is the total variance. However, when the fraction of the variance is plotted as the cumulative sum divided by the total variance (Fig. 4b) the model and observations have similar fractions of the variance as a function of frequency. The half period $T_{1 / 2}$, which is the period where there is exactly half of the fraction of variance at higher and lower periods, is 231 and 382 days for the model and observations, respectively.

The jet axis latitude time series is shown in Figs. $2 \mathrm{c}$ and $2 \mathrm{~d}$. The mean and standard deviation of jet axis latitude in CESM is $35.6^{\circ} \pm 0.51^{\circ} \mathrm{N}$ and is in relatively good agreement with the observed jet axis latitude, $34.9^{\circ} \pm$ $0.65^{\circ} \mathrm{N}$. On average, the Kuroshio Extension takes a $0.7^{\circ}$ more northerly path in the model after separating from the coast of Japan. Overall, the jet axis latitude in CESM agrees in frequency space with observations (Fig. 3c). The observations have higher variance, but the fraction of variance in frequency space agrees again (Figs. 4c,d). The spectrum for jet axis latitude is more red than for the pathlength with a larger fraction of the variance summed up at low frequencies ( $T_{1 / 2}$ is 1062 and 1058 days for the model and observations, respectively).

Qiu and Chen (2005) argue that the pathlength tends to be longer when the jet is farther south and vice versa. They also argue that the jet latitude is correlated to the phase of the PDO. It will be shown in the next section that the same relationship between PDO and jet latitude 

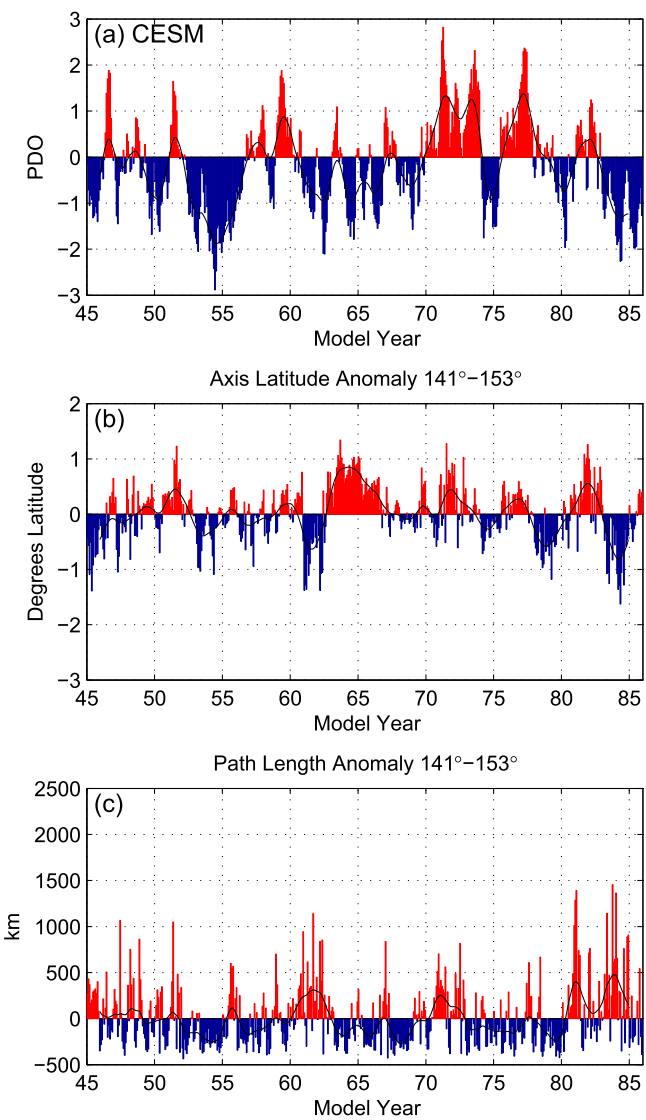
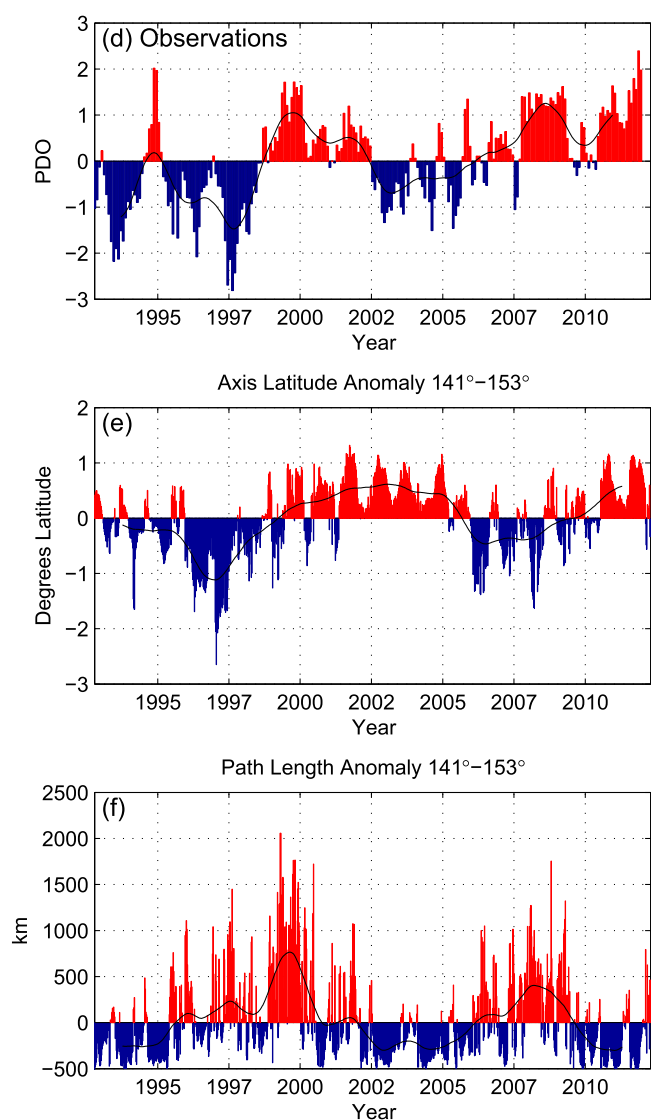

FIG. 5. Time series of PDO, jet axis latitude anomaly, and pathlength anomaly for model years (a)-(c) 45-86 and (d)-(f) observations. The black line is a 1-yr running mean. The HadISST dataset was used to calculate PDO for observations.

hold for CESM as in observations, but there is a $\sim 1$-yr lag between jet latitude and pathlength in both the model and observations that had not been detected previously.

\section{b. Pacific decadal oscillation and Kuroshio Extension variability}

In this section, it is shown that the Kuroshio Extension variability in CESM is correlated with the phase of the PDO on interannual to decadal time scales. The PDO in CESM agrees well with observations in frequency space with comparable variance at short and long time scales (Fig. 3a). Time series of the PDO, jet axis latitude anomaly, and pathlength anomaly are shown in Fig. 5. PDO is calculated as the first-mode empirical orthogonal function of SST in the Pacific north of $20^{\circ} \mathrm{N}$ (Mantua et al. 1997). In both the model and observations, the phase of the PDO (Figs. 5a,d) leads the jet axis latitude anomaly (Figs. 5 b,e) by $\sim 3-4 \mathrm{yr}$, which has led to some degree of predictability in the Kuroshio Extension system (Qiu et al. 2014). Following meridional shifts of the Kuroshio Extension (Figs. 5b,e), it transitions into different meandering states (Figs. 5c,f). When the Kuroshio Extension is farther north, it tends to be in a stable meandering state and vice versa.

The transition between meandering states and jet latitude is not coincident in time, however. Figure 6 shows a 3-yr, running-mean time series of PDO versus jet axis latitude anomaly (Figs. 6a,b) and jet axis latitude anomaly versus pathlength anomaly (Figs. 6c,d). Here, we have zoomed in on CESM time series for years 3041, which showed a particularly clear transition. In CESM and observations, there is a positive correlation between PDO and jet axis latitude with PDO leading by $\sim 3-4$ yr (Figs. 6a,b). There is negative correlation between the jet axis latitude anomaly and pathlength anomaly with jet axis latitude leading by $\sim 1-2 \mathrm{yr}$ (Figs. 6c,d). In other studies (e.g., Qiu and Chen 2005) it was implied that there was a simultaneous transition between meandering states with meridional shifts of the Kuroshio Extension jet. It is still an open question as to what mechanism is responsible for the change in degree of meandering of the jet after meridional shifts since a stronger jet is associated with weaker meandering. 

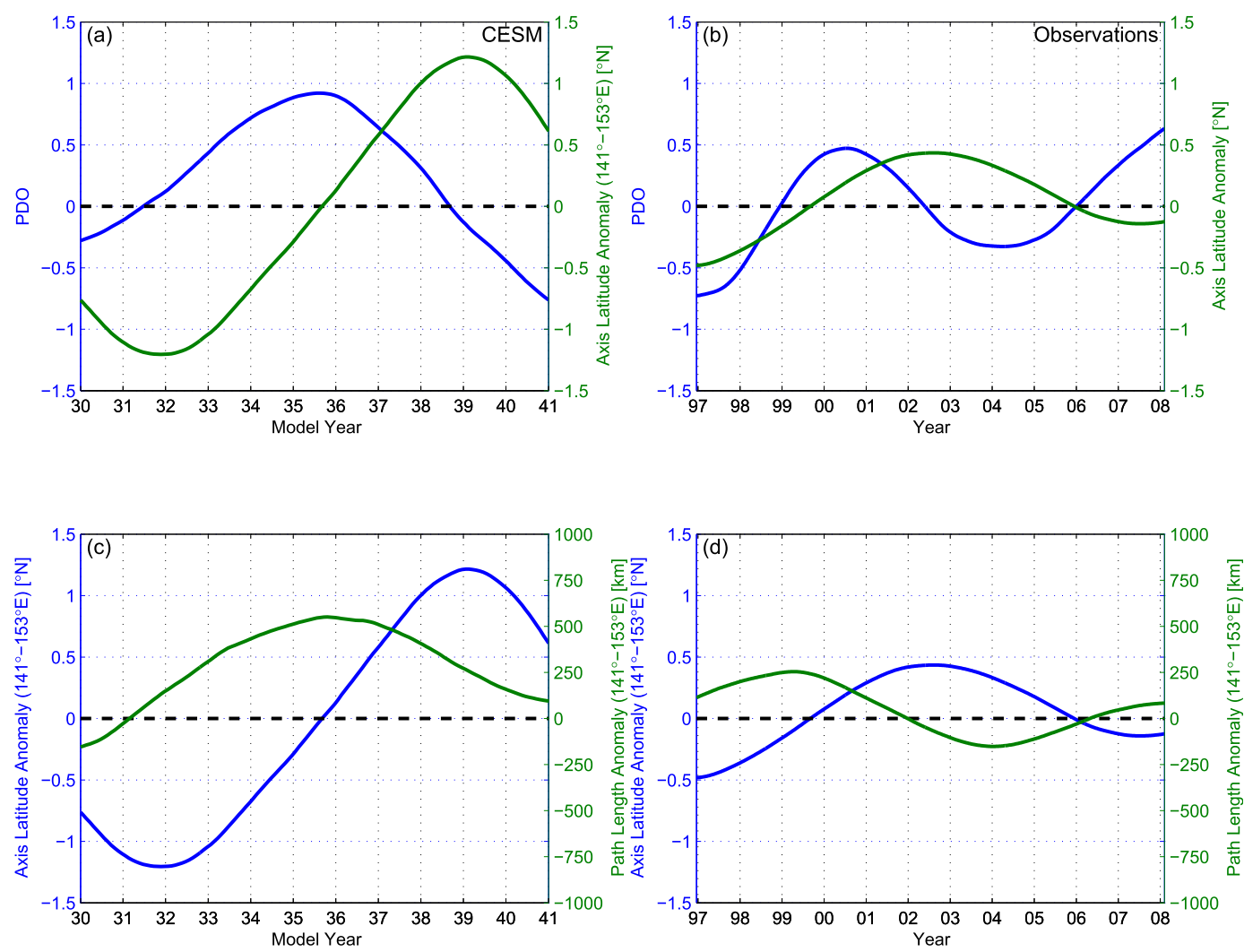

FIG. 6. (a) The 3-yr, running-mean PDO and jet axis latitude anomaly for model years 30-41 and (b) observations.

(c) The 3-yr running-mean jet axis latitude anomaly and pathlength anomaly for model years 30-41 and (d) observations.

The mechanism for meridional shifts of the Kuroshio Extension is still an active area of research but according to thin-jet theory are due to SSH anomalies originating in the eastern Pacific, which conserve their potential vorticity and this explains their amplitude increase as they approach the east coast of Japan (Sasaki et al. 2013). The sign of the SSH anomalies has also been found to be correlated with the phase of the PDO. The authors recognize that PDO is not a driving mechanism but rather the SST patterns that make up the PDO result from many factors, including wind stress curl patterns. Nonetheless, positive PDO is correlated with negative SSH anomalies thought to be the result of wind stress curl patterns related to the strengthening of the Aleutian low in the central Pacific. Negative PDO has the opposite effect. Once the SSH anomalies are generated, they propagate west as first baroclinic Rossby waves (Qiu and Chen 2005). In this study, we compare PDO and SSH anomalies as a metric for the model and observations and do not argue that this is irrefutable evidence for the driving mechanism in Kuroshio Extension variability. The PDO and SSH anomaly mechanism is indeed at play in CESM. Figure 7 shows a Hovmöller diagram of low-pass filtered SSH anomalies between $32^{\circ}$ and $34^{\circ} \mathrm{N}$ and $140^{\circ} \mathrm{E}$ and $130^{\circ} \mathrm{W}$ [similar to Fig. 6 in Qiu and Chen (2010)]. The arrival of positive SSH anomalies in the Kuroshio Extension region 3-4 yr after they appear in the central North Pacific is followed by a northward shift and a subsequent strengthening of the jet. The opposite occurs for negative SSH anomalies.

\section{c. Kuroshio Extension index}

To quantify the effects of Kuroshio Extension variability on atmospheric circulation and meridional heat transport, a KEI is calculated from the wintertime pathlength in Fig. 8a. KEI was calculated as the negative, normalized, wintertime pathlength in Fig. 8a (Fig. 8c). Defined in this way, positive KEI values indicate stable meandering states. The value $|\mathrm{KEI}| \geq 0.25$ will be used as the threshold to define composite meandering regimes throughout this paper, which allows for enough realizations for statistical significance (19 and $15 \mathrm{yr}$ for stable and unstable composites, respectively).

Figures $8 \mathrm{~d}$ and $8 \mathrm{e}$ show a composite of SSH and EKE for stable and unstable meandering conditions. The stable composite has a sharp SSH front $(\Delta \mathrm{SSH}$ of 

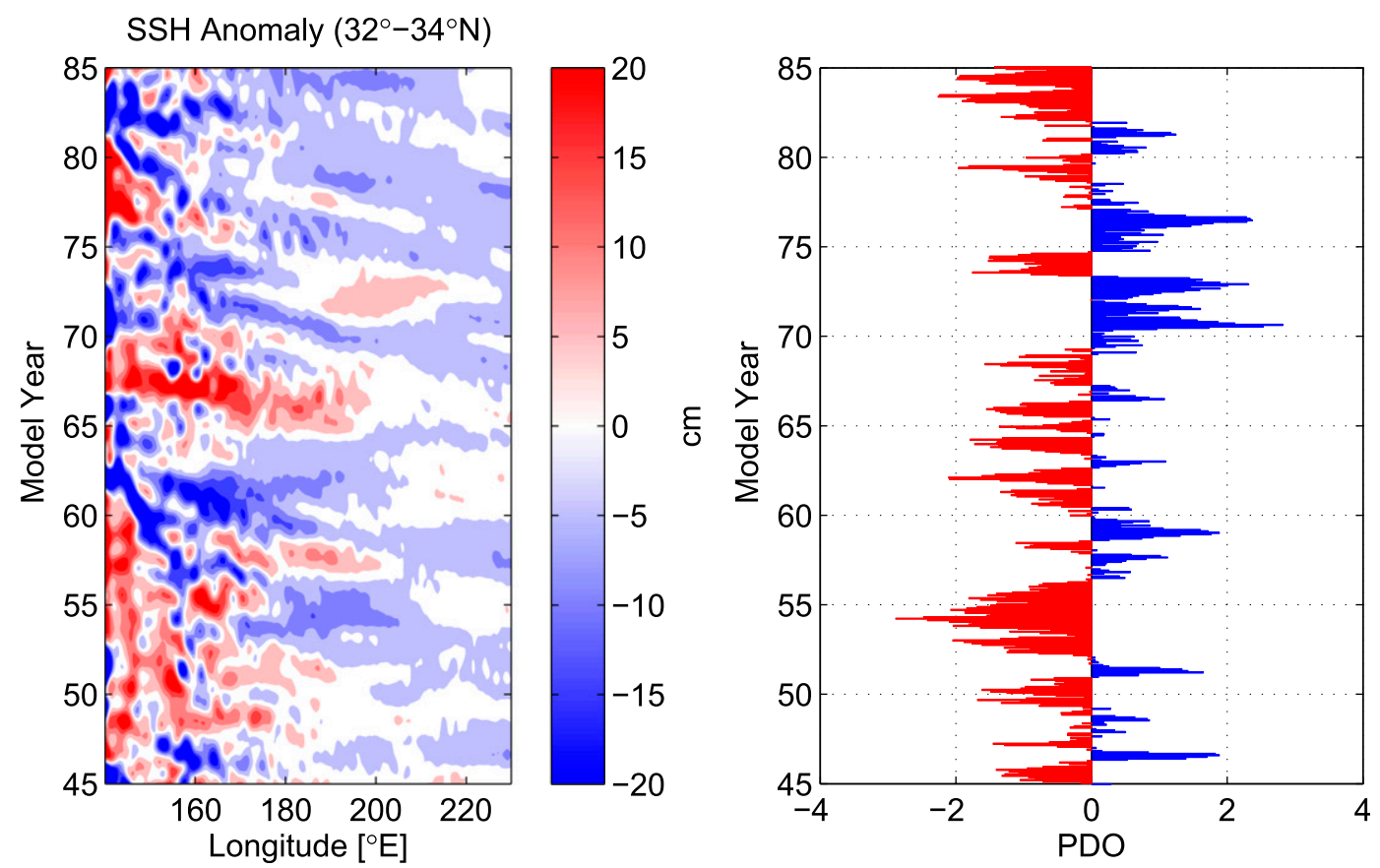

FIG. 7. CESM, low-pass filtered, SSH anomaly Hovmöller diagram $\left(32^{\circ}-34^{\circ} \mathrm{N}\right)$ (left) and PDO (right).

$84 \mathrm{~cm}$ between $34^{\circ}$ and $36^{\circ} \mathrm{N}$ at $145^{\circ} \mathrm{E}$ ) with modest EKE in the vicinity of the front. The stable composite demonstrates a stronger Kuroshio Extension transport and a well-pronounced southern recirculation gyre. The unstable composite has a much weaker front $\left(\Delta \mathrm{SSH}\right.$ of $60 \mathrm{~cm}$ between $34^{\circ}$ and $36^{\circ} \mathrm{N}$ at $\left.145^{\circ} \mathrm{E}\right)$ and a larger breadth of high EKE. The unstable composite demonstrates, contrary to the stable composite, a much weaker Kuroshio Extension transport and southern recirculation gyre.

The characteristics between stable and unstable meandering states are further shown from a regression of monthly SSH onto KEI and normalized monthly jet axis latitude (Fig. 9). During the stable meandering state, when the pathlength is short, SSH is higher to the south and lower to the north between $140^{\circ}$ and $155^{\circ} \mathrm{E}$ (Fig. 9a). This indicates that the SSH gradient is higher, which would imply also that the geostrophic transport of the Kuroshio Extension is higher during stable meandering states and vice versa. $\mathrm{SSH}$ is also higher along mean $\mathrm{SSH}$ contours when the jet axis latitude is north (Fig. 9b). These simulated relationships are in accordance with observations. Interestingly, in the region where the large meander tends to occur $\left(135^{\circ}-140^{\circ} \mathrm{E}\right)$, there is anomalously low SSH during stable meandering regimes. This indicates that there may be a relationship between EKE between $141^{\circ}$ and $153^{\circ} \mathrm{E}$ and the presence of the large meander upstream in connection with the phase of the PDO not explored in this paper.

\section{Wintertime, atmospheric response to Kuroshio Extension variability}

In this section, the wintertime atmospheric response to the Kuroshio Extension variability is explored. In particular, the difference between surface heat fluxes through the air-sea interface $Q_{o}$ and atmospheric meridional eddy heat transport differences based on the KEI are investigated.

\section{a. Surface heat flux}

The largest $Q_{o}$ from the ocean to the atmosphere occurs during cold air outbreaks in the winter months in the WBC regions (Jensen et al. 2011). Daily values exceeding $800 \mathrm{~W} \mathrm{~m}^{-2}$ were observed over the Gulf Stream during the CLIVAR Mode Water Dynamics Experiment (CLIMODE), a 5-yr intensive field program in the wintertime Gulf Stream from 2004 to 2009 (Marshall et al. 2009). The convention adopted here is that positive values indicate that the fluxes are from the ocean to the atmosphere, that is, the ocean is losing heat. Figure 10 shows a composite of wintertime $Q_{o}$ for the model and observations for stable and unstable meandering regimes in the Kuroshio Extension region. The stable (Fig. 10a) and unstable regimes (Fig. 10c) have qualitatively similar characteristics with the largest $Q_{o}$ occurring along the jet axis with maximum $Q_{o}$ exceeding $500 \mathrm{Wm}^{-2}$ in the model. CESM has greater magnitude $Q_{o}$ than observations by $50-100 \mathrm{~W} \mathrm{~m}^{-2}$ (Fig. 10b,d). 

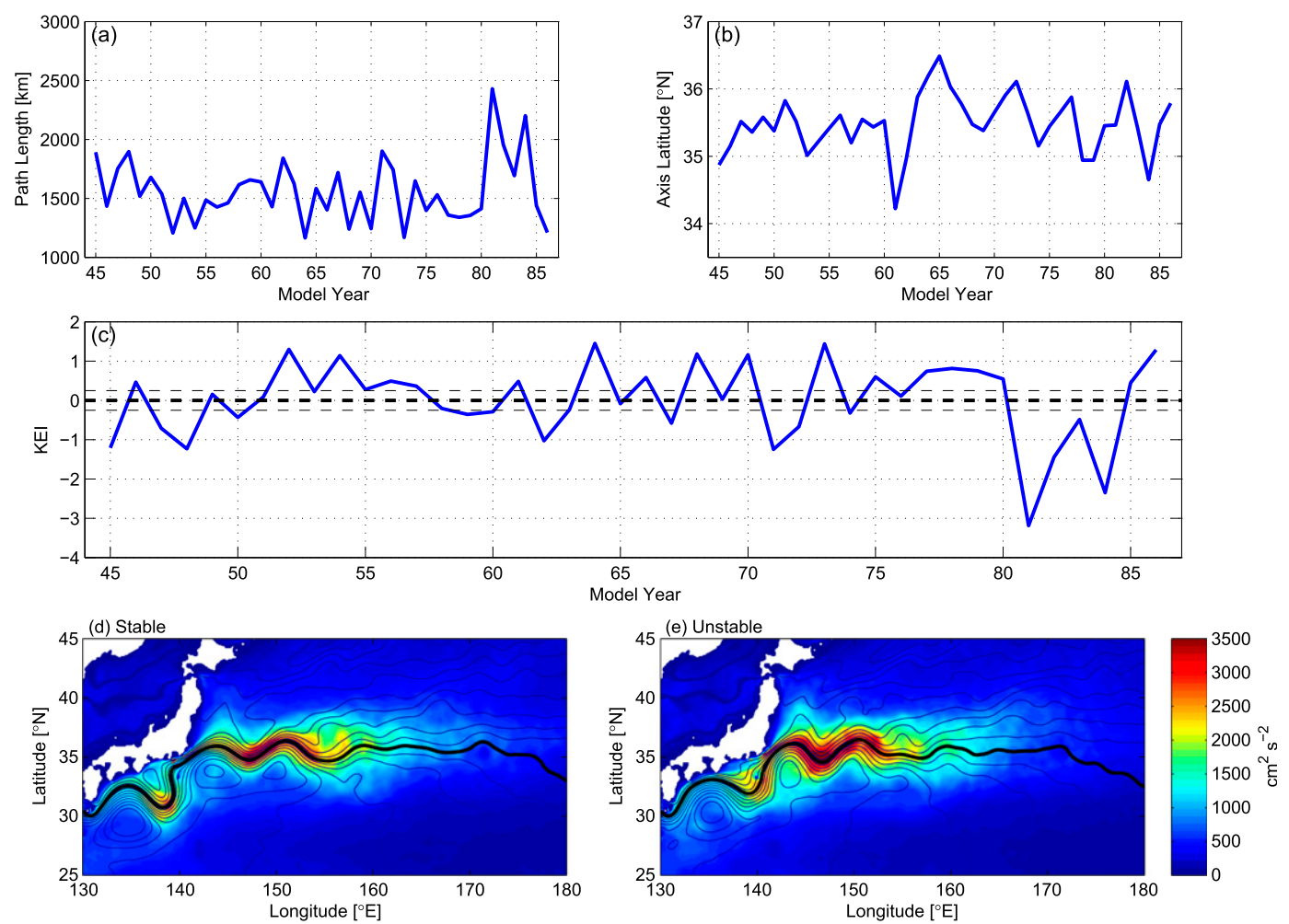

FIG. 8. CESM wintertime (JFM) (a) pathlength, (b) jet axis latitude, and (c) KEI for model years 45-86. The thin dashed line is \pm 0.25 . Composites of annual-mean (d) EKE (color contours, ci $=50 \mathrm{~cm}^{2} \mathrm{~s}^{-2}$ ) and (e) SSH (black contours, $\mathrm{ci}=10 \mathrm{~cm}$ ) for stable and unstable meandering regimes. The thick black contour is the $60-\mathrm{cm} \mathrm{SSH} \mathrm{contour}$ representing the jet axis.

The difference between stable and unstable composites (stable minus unstable) of $Q_{o}$ is shown in Fig. 10e for the model and Fig. 10f for the observations. Figure $10 \mathrm{f}$ looks very close to Fig. 3b in O'Reilly and Czaja (2015) even though O'Reilly and Czaja (2015) used a more conservative threshold for their composite ( \pm 1 instead of \pm 0.25$)$. A regression of $Q_{o}$ onto the KEI shows a qualitatively similar geographic structure as the composite difference. Overall, the difference between stable and unstable composites in the model and observations is similar in magnitude and geographic distribution. During stable regimes, the Kuroshio Extension loses more heat south of $35^{\circ} \mathrm{N}$; the difference in heat flux between regimes is on the order of $50 \mathrm{~W} \mathrm{~m}^{-2}$ between $140^{\circ}$ and $150^{\circ} \mathrm{E}$. There is a large decrease in heat loss north of $35^{\circ} \mathrm{N}$. The sense of the surface heat flux differences is such that the atmosphere is warmed more to the south during the stable regime, thereby enhancing the low-level baroclinicity.

\section{b. Atmospheric meridional heat transport}

We will make the distinction between mean and eddy components of meridional heat transport. Meridional heat transport can be decomposed into a time-mean (mean) and transient (eddy) component. The meridional heat transport for the atmosphere [Eq. (7)] decomposed in this way is

$$
\mathscr{H}^{a}=\underbrace{\oint \int_{0}^{h_{a}} \rho_{a} C_{p}^{a} \bar{v}_{a} \bar{T}_{a} d z d x}_{\mathscr{H}_{\text {mean }}^{a}}+\underbrace{\oint \int_{0}^{h_{a}} \rho_{a} C_{p}^{a} \overline{v_{a}^{\prime} T_{a}^{\prime}} d z d x}_{\mathscr{H}_{\text {eddy }}^{a}} .
$$

Primes here indicate a deviation from the time mean. During stable states of the Kuroshio Extension, it is expected that the ocean will have a lower meridional eddy heat transport and vice versa for unstable states. This was seen for one transition from a stable to unstable meandering state in KESS observations (Bishop 2013), but the results are not statistically significant due to only capturing one realization and the shortness of the record (16 months). However, this does not preclude a change in oceanic mean transport, which will be shown in the next section. In contrast with the ocean, the atmosphere in the midlatitudes is dominated by the jet stream variability, and meridional heat transport is largely due to the eddy component $\mathscr{H}^{a} \approx \mathscr{H}_{\text {eddy }}^{a}$. Enhanced ocean-toatmosphere surface heat fluxes on the southern side of 

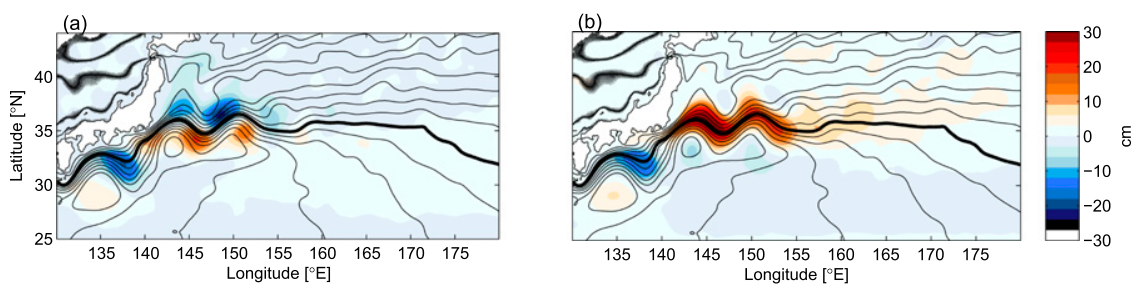

FIG. 9. SSH regression onto (a) KEI and (b) jet axis latitude for model years 45-86. Black contours are the mean SSH contours $(\mathrm{ci}=10 \mathrm{~cm})$. The thick black contour is the $60-\mathrm{cm} \mathrm{SSH}$ contour representing the jet axis.

the Kuroshio Extension during the stable meandering state suggests that $\mathscr{H}_{\text {eddy }}^{a}$ would possibly be increased during stable states and decreased during unstable states because of an increase in lower-atmospheric baroclinicity as described above. The unstable meandering state of the Kuroshio Extension essentially acts to smooth the SST front, and the response may be expected to be as described by the SST smoothing experiments of Small et al. (2013).

In the atmosphere, there are two components that make up $\mathscr{H}_{\text {eddy }}^{a}$ : contributions from sensible and latent heat advection. Following Kwon and Joyce (2013), the vertically integrated, atmospheric, meridional eddy heat flux in pressure coordinates from 50 to $1000 \mathrm{hPa}$ is

$$
\frac{1}{g} \int_{p_{0}}^{p_{s}}\left(C_{p}^{a} \overline{v_{a}^{\prime} \theta_{a}^{\prime}}+L \overline{v_{a}^{\prime} q^{\prime}}\right) d p
$$

where $C_{p}^{a} \approx 1000 \mathrm{~J} \mathrm{~kg}^{-1} \mathrm{~K}^{-1}$ is the specific heat of air at constant pressure; $L \approx 2.5 \times 10^{3} \mathrm{~J} \mathrm{~kg}^{-1}$ is the latent heat of vaporization; $p$ is the pressure; and $p_{0}$ and $p_{s}$ are the 50- and 1000-hPa pressure levels, respectively. Meridional eddy temperature and specific humidity flux were calculated from monthly averaged outputs as
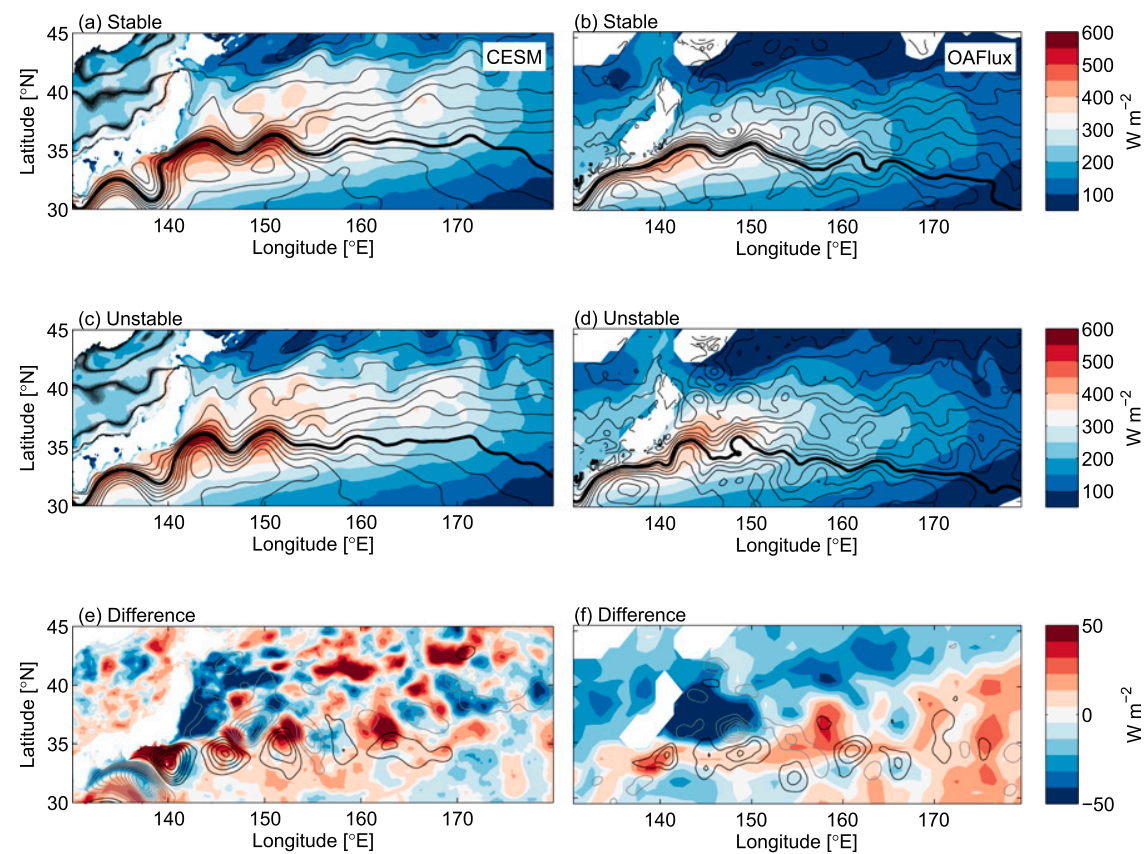

FIG. 10. Stable vs unstable wintertime (JFM) surface heat fluxes $Q_{o}$ for the model (left and observations (right). Composite for (a) stable and (c) unstable meandering regimes in the model (color contours, $\mathrm{ci}=25 \mathrm{~W} \mathrm{~m}^{-2}$ ) and SSH (black contours, $\mathrm{ci}=10 \mathrm{~cm}$ ). The thick black contour is the $60-\mathrm{cm} \mathrm{SSH}$ contour representing the jet axis. (e) Difference between the stable and unstable composite of model $Q_{o}$ (color contours, ci $=5 \mathrm{~W} \mathrm{~m}^{-2}$ ) and SSH (gray contours are negative and black are positive, ci $=5 \mathrm{~cm})$. (b),(d),(f) As in (a),(c), and (e), but for the OAFlux product for years 1993-2009. 


$$
\begin{aligned}
& \overline{v_{a}^{\prime} \theta_{a}^{\prime}}=\overline{v_{a} \theta_{a}}-\bar{v}_{a} \bar{\theta}_{a}, \quad \text { and } \\
& \overline{v_{a}^{\prime} q^{\prime}}=\overline{v_{a} q}-\bar{v}_{a} \bar{q},
\end{aligned}
$$

such that eddy in this case means a deviation from the monthly mean. The monthly estimates of meridional eddy heat and specific humidity flux include time scales from the model time step to a month. Other studies have made the distinction between the synoptic band (2-8 days) and intraseasonal band ( 8 days -3 months) for transient eddy heat flux (O'Reilly and Czaja 2015; Kwon and Joyce 2013). In this study, the focus will be on the submonthly band, which includes the synoptic band.

Wintertime, vertically integrated, meridional eddy heat flux [Eq. (13)] composites based on the KEI are shown in Fig. 11. There are larger atmospheric, meridional eddy heat fluxes during stable Kuroshio Extension meandering regimes (Fig. 11a) versus unstable meandering regimes (Fig. 11b). The difference between the stable and unstable composites is shown in Fig. 11c. There is a band of enhanced meridional eddy heat flux over the Kuroshio Extension region between $135^{\circ}$ and $155^{\circ} \mathrm{E}$ that extends northward and to the east with the largest differences occurring between $40^{\circ}$ and $50^{\circ} \mathrm{N}$ and $160^{\circ}$ and $175^{\circ} \mathrm{E}$. The maximum increase in vertically integrated, meridional eddy heat flux is $22 \%$ of the mean $\left(4.4 \times 10^{7}\right.$ vs $\left.20 \times 10^{7} \mathrm{~W} \mathrm{~m}^{-1}\right)$.

Atmospheric meridional eddy heat transport $\mathscr{H}_{\text {eddy }}^{a}$ was calculated across the Pacific sector by zonally integrating the vertically integrated meridional eddy heat flux [Eq. (13)] between $130^{\circ} \mathrm{E}$ and $160^{\circ} \mathrm{W}$. Instead of calculating time composites of $\mathscr{H}_{\text {eddy }}^{a}$ as a function of latitude, it was calculated referenced to the jet stream axis. Since the Kuroshio Extension migrates meridionally several degrees based on its dynamic state, we adopted a stream coordinate to compare time composites, which will be shown in the next section. To be consistent with our comparisons for the oceanic meridional heat transport, we adopted a similar method for the atmosphere. For each year, we remapped $\mathscr{H}_{\text {eddy }}^{a}$ to a stream coordinate with the jet stream axis as zero on the $y$ axis $\left[\mathscr{H}_{\text {eddy }}^{a}(y, t) \rightarrow \mathscr{H}_{\text {eddy }}^{a}\left(y_{s}, t\right)\right.$, where $y_{s}$ is the new $y$ coordinate based on the jet stream axis]. The jet stream axis is defined as the maximum $850-\mathrm{hPa}$, zonally averaged zonal wind between $130^{\circ} \mathrm{E}$ and $160^{\circ} \mathrm{W}$, which is consistent with Barnes and Polvani (2013) who used a pressure-weighted average between 700 and $850 \mathrm{hPa}$. The mean and standard deviation of the jet stream axis for model years $45-86$ are $39.2^{\circ} \pm 3.2^{\circ} \mathrm{N}$. The jet stream axis latitude composite based on KEI for stable years is $39.94^{\circ} \mathrm{N}$, and for unstable years it is $39.27^{\circ}$. On average the jet stream migrates to the north by $0.67^{\circ}$ when the Kuroshio Extension is in a stable state and also coincides
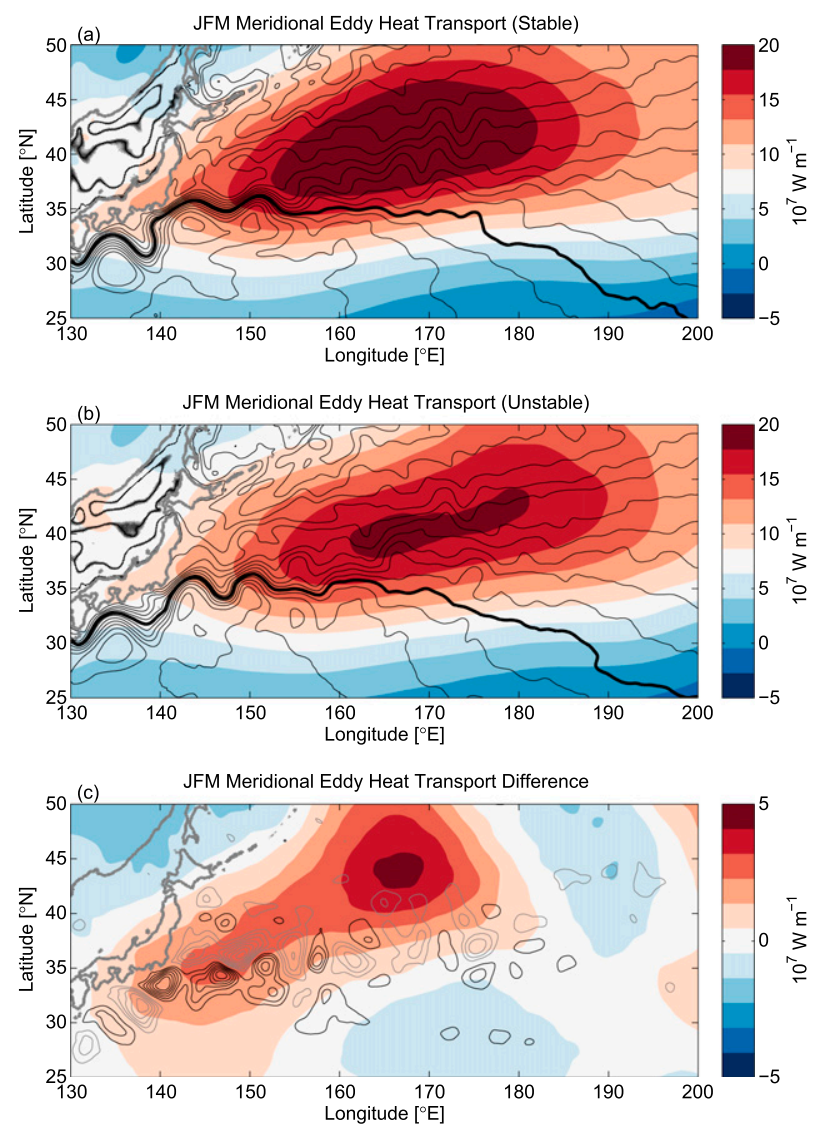

FIG. 11. Stable vs unstable wintertime (JFM) atmospheric meridional eddy heat flux. Composite of vertically integrated meridional eddy heat flux (color contours, $\mathrm{ci}=0.25 \times 10^{7} \mathrm{~W} \mathrm{~m}^{-1}$ ) and SSH contours (black contours, ci $=10 \mathrm{~cm}$ ) for model years $45-86$ for the (a) stable and (b) unstable meandering regimes. (c) Composite difference (stable minus unstable).

when the Kuroshio Extension takes a more northerly path. The time series of atmospheric $\mathscr{H}_{\text {eddy }}^{a}$ relative to the jet stream axis is shown in Fig. 12a. The $\mathscr{H}_{\text {eddy }}^{a}$ fluctuates interannually between 0.5 and $0.6 \mathrm{PW}(\mathrm{PW} \equiv$ $\left.10^{15} \mathrm{~W}\right)$ at the jet stream axis. Composites of $\mathscr{H}_{\text {eddy }}^{a}$ based on KEI are shown in Fig. 12b. The stable Kuroshio Extension meandering state corresponds to higher-atmospheric $\mathscr{H}_{\text {eddy }}^{a}$ between $130^{\circ} \mathrm{E}$ and $160^{\circ} \mathrm{W}$ (Fig. 12c). At the jet stream axis, $\mathscr{H}_{\text {eddy }}^{a}$ is $0.1 \pm 0.03 \mathrm{PW}$ higher during the stable meandering regime, with the maximum difference of $0.11 \pm 0.03 \mathrm{PW}$ occurring $240 \mathrm{~km}$ north of the jet stream axis (Fig. 12c), which is $41.4^{\circ} \mathrm{N}$ in reference to the mean jet stream path of $39.2^{\circ} \mathrm{N}$.

\section{Oceanic meridional heat transport}

Oceanic meridional heat transport is calculated for the North Pacific as 

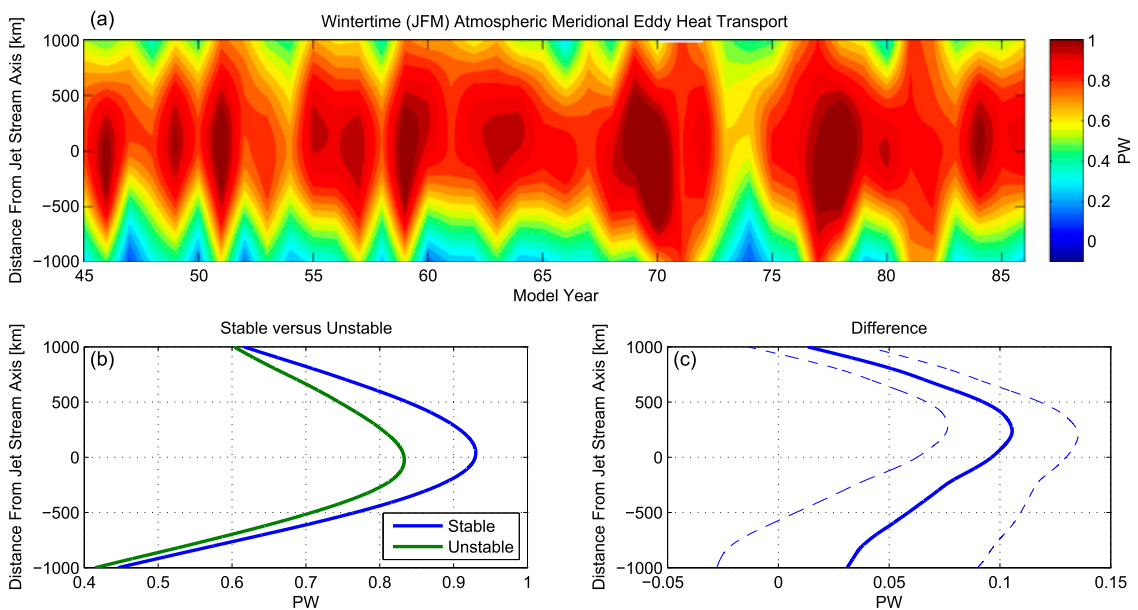

FIG. 12. Stable vs unstable wintertime (JFM) MEHT relative to the jet stream axis. (a) Time series of MEHT. (b) Composite of MEHT for stable vs unstable Kuroshio Extension meandering regimes. (c) Difference in MEHT between stable and unstable meandering regimes. Blue dashed lines are \pm the standard error of the composite difference.

$$
\begin{aligned}
\mathscr{H}^{o}= & \underbrace{\rho_{o} C_{p}^{o} \int_{x_{w}}^{x_{e}} \int_{-h_{o}}^{0} \bar{v}_{o} \bar{T}_{o} d z d x}_{\mathscr{H}_{\text {mean }}^{o}} \\
& +\underbrace{\rho_{o} C_{p}^{o} \int_{x_{w}}^{x_{e}} \int_{-h_{o}}^{0} \overline{v_{o}^{\prime} T_{o}^{\prime}} d z d x}_{\mathscr{H}_{\text {eddy }}^{o}},
\end{aligned}
$$

where $\rho_{o}$ is the average density over the region; $C_{p}^{o} \approx 4000 \mathrm{~J} \mathrm{~kg}^{-1} \mathrm{~K}^{-1}$ is the specific heat of ocean water at constant pressure; and $x_{w}$ and $x_{e}$ are the western and eastern longitudes at the boundaries of the ocean basin. Because of the longer time scales of variability in the ocean and the importance of the mesoscale (times scales of days to months), annual averages of $\mathscr{H}^{\circ}$ are calculated. The term $\mathscr{H}_{\text {eddy }}^{o}$ was calculated from annual-mean meridional heat transport $\overline{v_{o} T_{o}}$ and annual-mean $\bar{v}_{o}$ and $\bar{T}_{o}$ as in Eq. (14), but the bar here indicates an annual mean. The value $\mathscr{H}_{\text {eddy }}^{o}$ then contains time scales from the model time step up to a year.

Time series of total $\mathscr{H}^{\circ}$, mean $\mathscr{H}_{\text {mean }}^{o}$, and eddy $\mathscr{H}_{\text {eddy }}^{o}$ oceanic meridional heat transport are shown in Fig. 13 (left column). The term $\mathscr{H}^{\circ}$ drops with latitude and ranges from 0.25 to $0.55 \mathrm{PW}$ at $33^{\circ}-38^{\circ} \mathrm{N}$ (Fig. 13, top left). The value $\mathscr{H}_{\text {mean }}^{o}$ also drops with latitude, but has a larger meridional gradient with range from 0.1 to 0.5 PW (Fig. 13, middle left). The $\mathscr{H}_{\text {eddy }}^{o}$ varies with a range of $\pm 0.1 \mathrm{PW}$, with a distinct minimum south of the Kuroshio Extension latitude.

Composites of oceanic meridional heat transport components based on KEI as a function of distance from the Kuroshio Extension latitude are shown in Fig. 13 (right column). The total meridional heat transport is higher during unstable meandering states mainly focused around the jet axis (Fig. 13, top right). When the total meridional heat transport is partitioned into mean and eddy components, the mean transport is higher during unstable states near the jet axis but is weaker south of the jet (Fig. 13, middle right). A composite of $\mathscr{H}_{\text {eddy }}^{o}$ reveals that the stable meandering regime tends to have equatorward (negative) $\mathscr{H}_{\text {eddy }}^{o}$ just south of the jet axis (Fig. 13, bottom left and right). The unstable meandering regime has a larger positive $\mathscr{H}_{\text {eddy }}^{o}$ just south of the Kuroshio Extension jet axis of $0.07 \pm 0.02 \mathrm{PW}$. North of the jet axis, there is no statistically significant difference in oceanic $\mathscr{H}_{\text {eddy }}^{o}$. From the composite differences (stable minus unstable), $\mathscr{H}^{\circ}$ is higher by a maximum of $0.04 \pm$ 0.03 PW near the jet core during unstable states (Fig. 14). The term $\mathscr{H}_{\text {mean }}^{o}$ is the component near the jet axis that is responsible for this difference. South of the jet, it is the presence of positive $\mathscr{H}_{\text {eddy }}^{o}$ during unstable states that makes up this difference. It is noted that the mean transport difference to the south is partially compensated by the eddy transport difference but not to the north where there are no differences in $\mathscr{H}_{\text {eddy }}^{o}$ between the stable and unstable regimes.

\section{Discussion and conclusions}

\section{a. Bjerknes compensation}

Meridional heat transport in the ocean and atmosphere composited with KEI shows that there is evidence for Bjerknes-like compensation during winter in the North Pacific based on Kuroshio Extension variability. As 

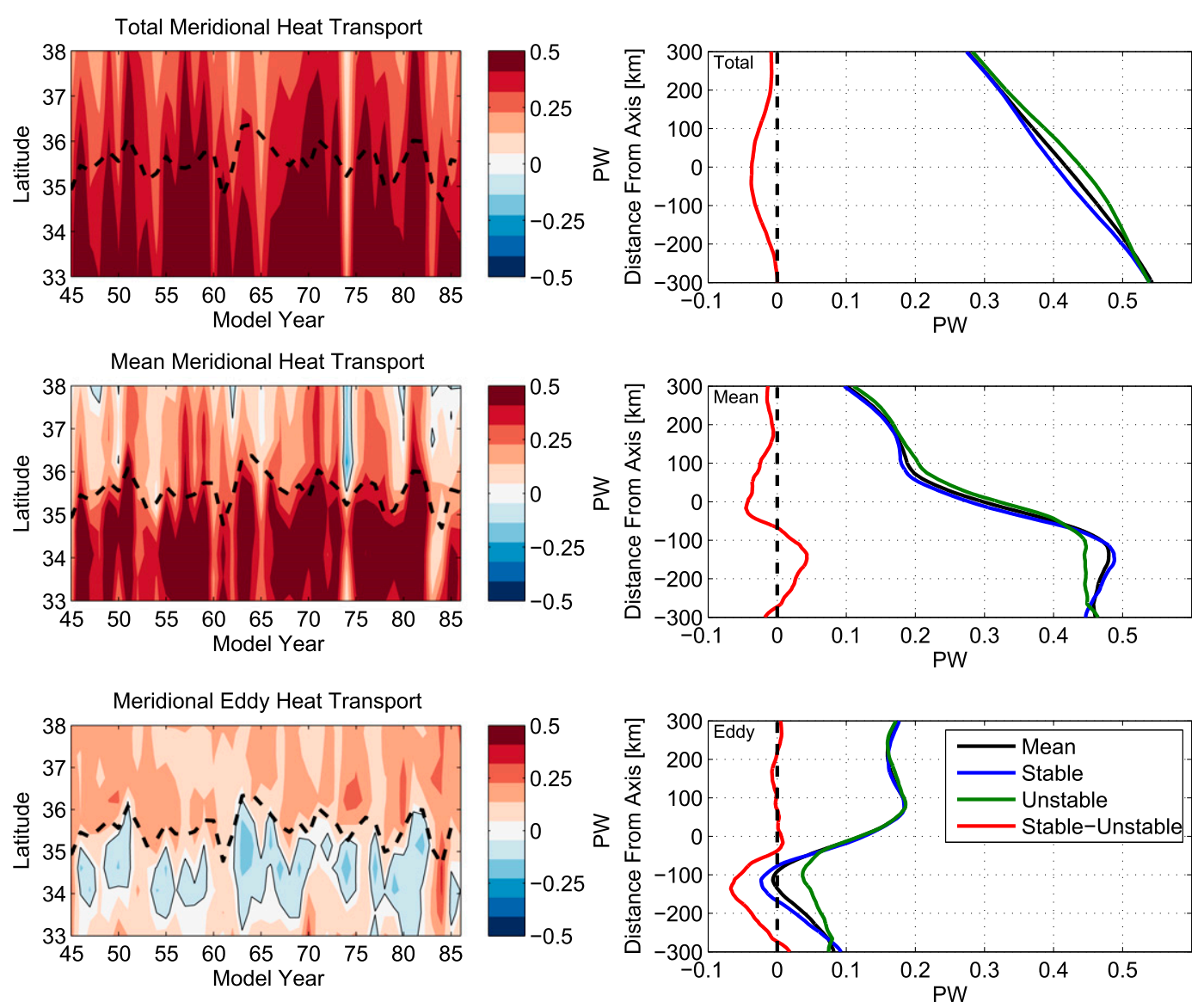

FIG. 13. North Pacific annual-mean oceanic meridional heat transport. Time series of (top left) total meridional heat transport, (middle left) mean meridional heat transport, and (bottom left) meridional eddy heat transport with the zero contour in thin black. The thick black dashed line is the Kuroshio Extension jet latitude (Fig. 8b). Stable vs unstable composite of (top right) total meridional heat transport, (middle right) mean meridional heat transport, and (bottom right) meridional eddy heat transport relative to the Kuroshio Extension jet axis latitude.

mentioned earlier, this compensation is not "true" Bjerknes compensation. The atmospheric meridional heat transport is responding to variability in the Kuroshio Extension. The results were surprising since it was not expected that the total meridional heat transport would be nearly compensated locally since this can take place anywhere on the globe.

When the Kuroshio Extension is in an unstable state, the meridional heat transport is increased partially due to mesoscale eddy activity and partially due to mean transport changes. The mean heat transport is suspected to be higher near the jet axis because of an increase in amplitude of the standing meander in the lee of the Izu-Ogasawara Ridge (Figs. 8d,e). To compare with observations, the oceanic $\mathscr{H}_{\text {eddy }}^{o}$ is increased in excess of $0.05 \mathrm{PW}$ during unstable states in the model. This is approximately the same value of $\mathscr{H}_{\text {eddy }}^{o}$ change between stable and unstable states calculated from KESS observations (Bishop 2013). During the unstable state, the Kuroshio Extension has a weaker meridional SSH and SST front, which results in lower wintertime $Q_{o}$ by $\sim 50 \mathrm{~W} \mathrm{~m}^{-2}$ to the south. The wintertime atmospheric storm track then has a weaker response with lower $\mathscr{H}_{\text {eddy }}^{a}$ by $\sim 0.1 \mathrm{PW}$ north of the Kuroshio Extension between $40^{\circ}$ and $45^{\circ} \mathrm{N}$. When the Kuroshio Extension transitions to a stable meandering state, the opposite effect takes place. A schematic of the meridional heat transport by the ocean and atmosphere during the two meandering states of the Kuroshio Extension are shown in Fig. 15.

An interesting characteristic of the Kuroshio Extension stable meandering state is the presence of equatorward (negative) $\mathscr{H}_{\text {eddy }}^{\circ}$ south of the jet (Fig. 13, bottom left). The dominant source of variability in $\mathscr{H}_{\text {eddy }}^{o}$ just south of the Kuroshio Extension jet latitude is likely because of Western boundary current dynamics (Aoki et al. 2013). The fact that the jet axis latitude is nearly always just north of negative $\mathscr{H}_{\text {eddy }}^{o}$ also points to the Kuroshio Extension variability 


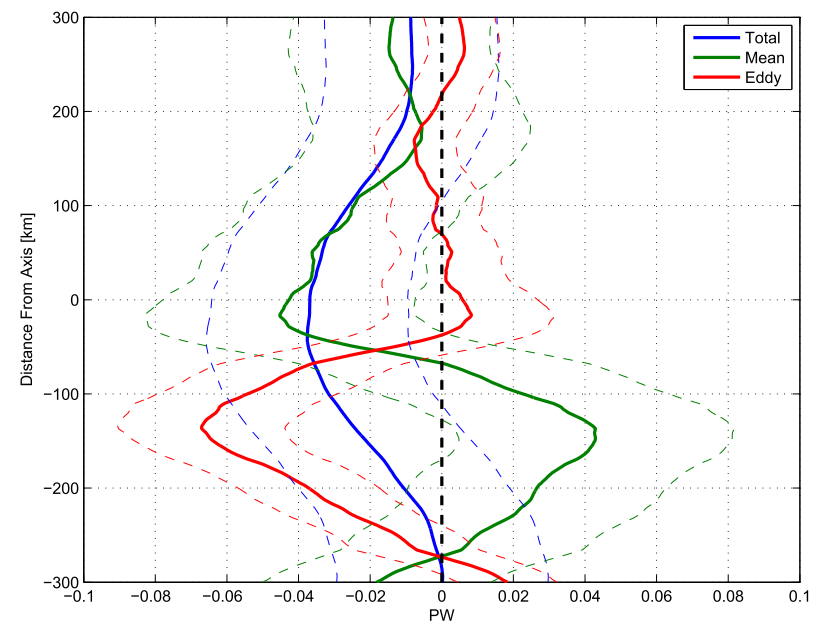

FIG. 14. Composite difference (stable minus unstable) for the total, mean, and eddy meridional heat transport. The dashed lines are \pm the standard error of the mean of the composite differences.

playing the dominant role in negative $\mathscr{H}_{\text {eddy }}^{o}$ across the Pacific. Aoki et al. (2013) found persistent equatorward $\mathscr{H}_{\text {eddy }}^{o}$ along the southern flanks of the Kuroshio Extension and Gulf Stream. These estimates of $\mathscr{H}_{\text {eddy }}^{o}$ were only for $5 \mathrm{yr}$ using the OGCM for the Earth Simulator (OFES). Here, the composite using $42 \mathrm{yr}$ of data shows that the unstable meandering regime has positive values of $\mathscr{H}_{\text {eddy }}^{o}$ in excess of $0.05 \mathrm{PW}$ on the southern flanks of the Kuroshio Extension and that the overall mean of $\mathscr{H}_{\text {eddy }}^{o}$ is near zero (Fig. 13, bottom right). A future paper will address the mechanisms for positive and negative $\mathscr{H}_{\text {eddy }}^{o}$ on the southern flanks of the Kuroshio Extension.

\section{b. Conclusions}

In this work, it is shown that the Kuroshio Extension variability compared with observations is well represented in a fully coupled high-resolution simulation of CESM. Variations in PDO lead Kuroshio Extension meandering states by $\sim 3-4 \mathrm{yr}$, and meridional shifts of the jet correspond with transitions in the meandering state. A new result here, that was not clear in other work, is that meridional shifts in the Kuroshio Extension jet do not lead to an instantaneous response in mesoscale eddy activity. Once the Kuroshio Extension shifts north or south, there is a corresponding lag of $\sim 1 \mathrm{yr}$ in pathlength response. The exact mechanism for why the Kuroshio Extension transitions to a higher or lower mesoscale eddy activity based on meridional shifts of the jet is still an open question, but observational evidence of jettopography interaction downstream at Shatsky Rise may hold the answers (Greene et al. 2012). Future work will hopefully address this missing link.

Using observations and a high-resolution fully coupled simulation of CESM, this study shows that there is evidence for a Bjerknes-like compensation in the North Pacific. The compensation is during wintertime and based on air-sea interaction at the Kuroshio Extension. North Pacific oceanic meridional heat transport varies on decadal time scales in association with variability in the Kuroshio Extension mesoscale eddy activity. When oceanic meridional heat transport is smaller than in other years, there is a wintertime atmospheric compensation of $\sim 0.1 \mathrm{PW}$, which corresponds to a maximum increase in vertically integrated meridional eddy heat transport (MEHT) of $22 \%$ compared to the mean. The

\section{Stable}

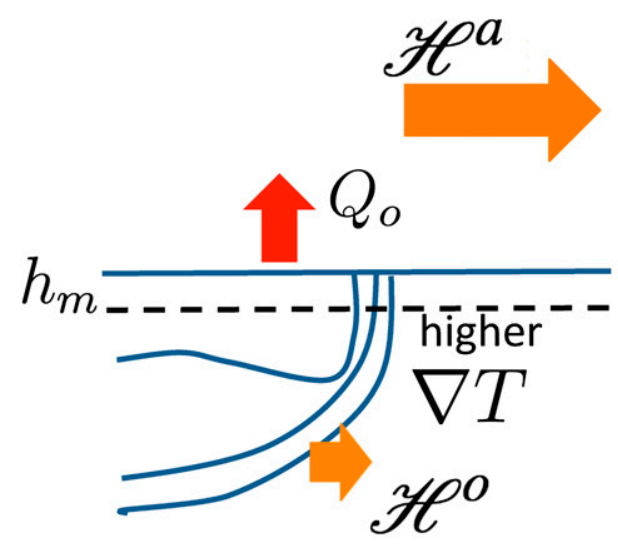

\section{Unstable}

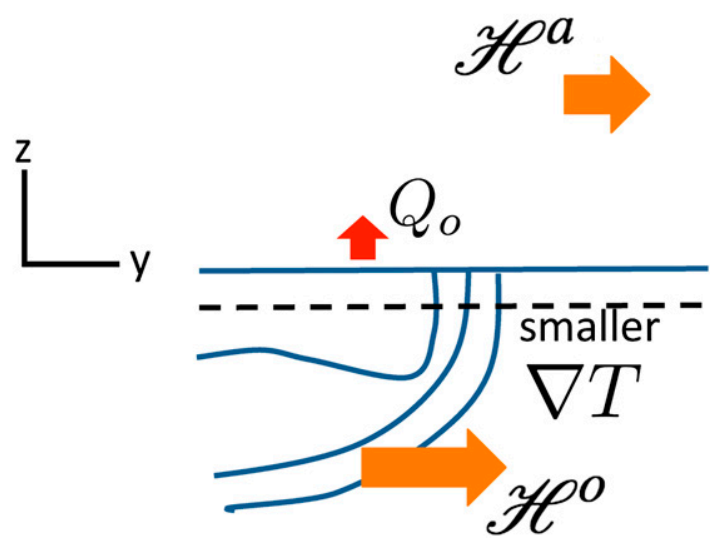

FIG. 15. Schematic diagram of North Pacific meridional heat transport compensation between the ocean $\mathscr{H}^{\circ}$ and atmosphere $\mathscr{H}^{a}$ based on the meandering state of the Kuroshio Extension (orange arrows). The term $h_{m}$ is the mixed layer depth, and $Q_{o}$ is the surface heat flux (red arrows). 
effects may be more than local. Enhanced atmospheric $\mathscr{H}_{\text {eddy }}^{a}$ during stable Kuroshio Extension regimes may lead to differences in jet stream variability downstream that is not explored in this paper. Chen and Yoon (2002) note the possible connection between North Pacific wintertime blocking and the phase of the PDO. Explicitly resolving mesoscale eddies in climate models has a nontrivial effect on decadal variability in the Kuroshio Extension and air-sea interaction that is missed in standard coarse climate simulations. Future efforts should focus on resolving mesoscale eddies in climate simulations such that natural climate variations on decadal time scales can be better understood.

Acknowledgments. This work was supported by the Advanced Study Program at the National Center for Atmospheric Research (NCAR). We thank Ari Solomon and comments from two anonymous reviewers that greatly improved the manuscript. We also thank Alison Baker and Andy Mai for their assistance in running these experiments. Computational resources for the simulation analyzed here were provided by the NCAR Computational and Information Systems Lab (CISL) under the "Accelerated Scientific Discovery" program.

\section{REFERENCES}

Aoki, K., S. Minobe, Y. Tanimoto, and Y. Sasai, 2013: Southward eddy heat transport occurring along southern flanks of the Kuroshio Extension and the Gulf Stream in a $1 / 10^{\circ}$ global ocean general circulation model. J. Phys. Oceanogr., 43, 18991910, doi:10.1175/JPO-D-12-0223.1.

Barnes, E. A., and L. Polvani, 2013: Response of the midlatitude jets, and of their variability, to increased greenhouse gases in CMIP5 models. J. Climate, 26, 7117-7135, doi:10.1175/ JCLI-D-12-00536.1.

Bishop, S. P., 2013: Divergent eddy heat fluxes in the Kuroshio Extension at $143^{\circ}-149^{\circ}$ E. Part II: Spatiotemporal variability. J. Phys. Oceanogr., 43, 2416-2431, doi:10.1175/JPO-D-13-061.1.

_- and F. O. Bryan, 2013: A comparison of mesoscale eddy heat fluxes from observations and a high-resolution ocean model simulation of the Kuroshio Extension. J. Phys. Oceanogr., 43, 2563-2570, doi:10.1175/JPO-D-13-0150.1.

Bjerknes, J., 1964: Atlantic air-sea interaction. Advances in Geophysics, Vol. 10,1-82, doi:10.1016/S0065-2687(08)60005-9.

Bryan, F. O., R. Tomas, J. Dennis, D. Chelton, N. Loeb, and J. McClean, 2010: Frontal scale air-sea interaction in highresolution coupled climate models. J. Climate, 23, 6277-6291, doi:10.1175/2010JCLI3665.1.

Chen, T.-C., and J.-H. Yoon, 2002: Interdecadal variation of the North Pacific wintertime blocking. Mon. Wea. Rev., 130, 3136-3143, doi:10.1175/1520-0493(2002)130<3136:IVOTNP > 2.0.CO;2.

Delman, A. S., J. L. McClean, J. Sprintall, L. D. Talley, E. Yulaeva, and S. R. Jayne, 2015: Effects of eddy vorticity forcing on the mean state of the Kuroshio Extension. J. Phys. Oceanogr., doi:10.1175/JPO-D-13-0259.1, in press.

Donohue, K. A., D. R. Watts, K. L. Tracey, M. Wimbush, and J.-H. Park, 2008: Program studies the Kuroshio Extension. Eos,
Trans. Amer. Geophys. Union, 89, 161-162, doi:10.1029/ 2008EO170002.

Douglass, E. M., S. R. Jayne, F. O. Bryan, S. Peacock, and M. E. Maltrud, 2012a: Kuroshio pathways in a climatologically forced model. J. Oceanogr., 68, 625-639, doi:10.1007/ s10872-012-0123-y.

,-- , S. Peacock, F. O. Bryan, and M. E. Maltrud, 2012b: Subtropical Mode Water variability in a climatologically forced model in the northwestern Pacific Ocean. J. Phys. Oceanogr., 42, 126-140, doi:10.1175/2011JPO4513.1.

Ducet, N., and P. Y. Le-Traon, 2001: A comparison of surface eddy kinetic energy and Reynolds stresses in the Gulf Stream and the Kuroshio current systems from merged TOPEX/Poseidon and ERS-1/2 altimetric data. J. Geophys. Res., 106, 1660316 622, doi:10.1029/2000JC000205.

England, M. H., and Coauthors, 2014: Recent intensification of wind-driven circulation in the Pacific and the ongoing warming hiatus. Nat. Climate Change, 4, 222-227, doi:10.1038/ nclimate2106.

Farneti, R., and G. K. Vallis, 2013: Meridional energy transport in the coupled atmosphere-ocean system: Compensation and partitioning. J. Climate, 26, 7151-7166, doi:10.1175/ JCLI-D-12-00133.1.

Gent, P. R., and J. C. McWilliams, 1990: Isopycnal mixing in ocean circulating models. J. Phys. Oceanogr., 20,150-155, doi:10.1175/ 1520-0485(1990)020<0150:IMIOCM > 2.0.CO;2.

_ , and Coauthors, 2011: The Community Climate System Model version 4. J. Climate, 24, 4973-4991, doi:10.1175/ 2011JCLI4083.1.

Gouretski, V., and K. Koltermann, 2004: WOCE global hydrographic climatology: A technical report. Berichte des Bundesamtes für Seeschifffahrt und HydrographieTech. Rep. 35, 52 pp.

Greene, A. D., D. R. Watts, G. G. Sutyrin, and H. Sasaki, 2012: Evidence of vertical coupling between the Kuroshio Extension and topographically controlled deep eddies. J. Mar. Res., 70, 719-747, doi:10.1357/002224012806290723.

Hunke, E., and W. Lipscomb, 2008: CICE: The Los Alamos sea ice model: Documentation and software user's manual, version 4.0. Los Alamos National Laboratory Tech. Rep. LA-CC-06012, $116 \mathrm{pp}$.

Hurrell, J. W., and Coauthors, 2013: The Community Earth System Model: A framework for collaborative research. Bull. Amer. Meteor. Soc., 94, 1339-1360, doi:10.1175/BAMS-D-12-00121.1.

Jayne, S. R., and Coauthors, 2009: The Kuroshio Extension and its recirculation gyres. Deep-Sea Res. I, 56, 2088-2099, doi:10.1016/j.dsr.2009.08.006.

Jensen, T. G., T. J. Campbell, R. A. Allard, R. J. Small, and T. A. Smith, 2011: Turbulent heat fluxes during an intense cold-air outbreak over the Kuroshio Extension region: Results from a high-resolution coupled atmosphere-ocean model. Climate Dyn., 61, 657-674, doi:10.1007/s10236-011-0380-0.

Kelly, K. A., R. J. Small, R. M. Samelson, B. Qiu, T. M. Joyce, Y.-O. Kwon, and M. F. Cronin, 2010: Western boundary currents and frontal air-sea interactions: Gulf Stream and Kuroshio Extension. J. Climate, 23, 5644-5666, doi:10.1175/ 2010JCLI3346.1.

Kirtman, B., and Coauthors, 2012: Impact of ocean model resolution on CCSM climate simulations. Climate Dyn., 39, 13031328, doi:10.1007/s00382-012-1500-3.

Kosaka, Y., and S.-P. Xie, 2013: Recent global-warming hiatus tied to equatorial Pacific surface cooling. Nature, 501, 403-407, doi:10.1038/nature12534. 
Kwon, Y.-O., and T. M. Joyce, 2013: Northern Hemisphere winter atmospheric transient eddy heat fluxes and the Gulf Stream and Kuroshio-Oyashio Extension variability. J. Climate, 26, 9839-9859, doi:10.1175/JCLI-D-12-00647.1.

Large, W. G., and S. G. Yeager, 2009: The global climatology of an interannually varying air-sea flux data set. Climate Dyn., 33, 341-364, doi:10.1007/s00382-008-0441-3.

Lawrence, D., and Coauthors, 2011: Parameterization improvements and functional and structural advances in version 4 of the Community Land Model. J. Adv. Model. Earth Syst., 3, M03001, doi:10.1029/2011MS000045.

Mantua, N. J., S. R. Hare, Y. Zhang, J. M. Wallace, and R. C. Francis, 1997: A Pacific interdecadal climate oscillation with impacts on salmon production. Bull. Amer. Meteor. Soc., 78, 1069-1079, doi:10.1175/1520-0477(1997)078<1069:APICOW>2.0.CO;2.

Marshall, J., and Coauthors, 2009: The CLIMODE field campaign: Observing the cycle of convection and restratification over the Gulf Stream. Bull. Amer. Meteor. Soc., 90, 1337-1350, doi:10.1175/2009BAMS2706.1.

McClean, J., and Coauthors, 2011: A prototype two-decade fullycoupled fine-resolution CCSM simulation. Ocean Modell., 39, 10-30, doi:10.1016/j.ocemod.2011.02.011.

O'Reilly, C. H., and A. Czaja, 2015: The response of the Pacific storm track and atmospheric circulation to Kuroshio Extension variability. Quart. J. Roy. Meteor. Soc., 141, 52-66, doi:10.1002/qj.2334.

Qiu, B., and S. Chen, 2005: Variability of the Kuroshio Extension jet, recirculation gyre, and mesoscale eddies on decadal time scales. J. Phys. Oceanogr., 35, 2090-2103, doi:10.1175/JPO2807.1.
— and - 2010: Eddy-mean flow interaction in the decadally modulating Kuroshio Extension system. Deep-Sea Res. II, 57, 1098-1110, doi:10.1016/j.dsr2.2008.11.036.

,-- N. Schneider, and B. Taguchi, 2014: A coupled decadal prediction of the dynamic state of the Kuroshio Extension system. J. Climate, 27, 1751-1764, doi:10.1175/ JCLI-D-13-00318.1.

Rainville, L., S. R. Jayne, J. L. McClean, and M. E. Maltrud, 2007: Formation of Subtropical Mode Water in a high-resolution ocean simulation of the Kuroshio Extension region. Ocean Modell., 17, 338-356, doi:10.1016/j.ocemod.2007.03.002.

Reynolds, R., T. M. Smith, C. Liu, D. Chelton, K. Casey, and M. Schlax, 2007: Daily high-resolution-blended analysis for sea surface temperature. J. Climate, 20, 5473-5496, doi:10.1175/2007JCLI1824.1.

Sasaki, Y. N., S. Minobe, and N. Schneider, 2013: Decadal response of the Kuroshio Extension jet to Rossby waves: Observations and thin-jet theory. J. Phys. Oceanogr., 43, 442-456, doi:10.1175/JPO-D-12-096.1.

Small, R. J., R. A. Tomas, and F. O. Bryan, 2013: Storm track response to ocean fronts in a global high-resolution climate model. Climate Dyn., 43, 805-828, doi:10.1007/ s00382-013-1980-9.

_ , and Coauthors, 2015: A new high-resolution global climate simulation using Community Atmosphere Model version 5. J. Adv. Model. Earth Syst., 6, 1065-1094.

Yu, L., and R. Weller, 2007: Objectively analyzed air-sea heat fluxes for the global ice-free oceans (1981-2005). Bull. Amer. Meteor. Soc., 88, 527-539, doi:10.1175/BAMS-88-4-527. 